work of reference on sterols. A description of cholesterol and its simple derivatives occupies some 120 pages. These include accounts of physical properties, occurrence and formation, reactions and physiology, with descriptions of the addition compounds of cholesterol, its esters and its ethers. The steroid hormones, the bile acids, and the other main groups of steroids are reserved for future parts of the supplementary volume. Brief accounts of sterols of unknown structure may be expected to stimulate further research.

There is a description of the currently used steroid nomenclature, which has been adopted in the text, and the formuli show configurations so far as these are known. There are fifteen tables summarizing the properties of closely related sets of compounds, the index gives a complete list of naturally occurring compounds considered in the text, and there is a separate formula index. This book is particularly rich in editorial footnotes which correct errors in original papers, direct attention to uncertainties and ambiguities, and in many cases make valuable suggestions as to structures of compounds. One very minor error has been detected in the text-the name "conessine" is mis-spelt on p. 1392s. It is no longer true, as stated on p. 1382s, that $1: 2$-cyclopentadienophenanthrene has not yet been prepared, and this may have some bearing on the comments on pp. $1389 s$ and $1811 s$ about the $3^{\prime}$-methyl derivative.

Reaction schemes, which are a characteristic ferture of the "Encyclopædia", figure to some extent in the present work, examples being schemes showing the relationships of some of the cholestadienes ( $p$. $1419 s$ ) and the oxidative degradation of the sidechain and ring $D$ of cholesterol (p. 1583s). The biosynthesis of cholesterol is briefly discussed; but there is no mention of the use of precursors containing carbon isotopes. In spite of the excellent monographs on steroids which are available, this is a work which no one concerned with the chemistry of sterols can afford to be without. J. W. Cook

\section{TEXTILE PROGRESS}

\section{Review of Textile Progress}

Vol. 4, 1952 ; pp. 560; 35s. Vol. 5, 1953 ; pp. 588 ; $35 s$.

(Mànchester : Textile Institute ; Bradford : Society of Dyers and Colourists, 1953 and 1954.)

TEXTILE scientists and technologists have come to look forward to this annual "Review of Textile Progress", which usually appears towards the end of the year following that to which the account relates. Vols. 4 (1952) and 5 (1953) follow the same format as previous volumes, and the size of the book, which increased up to Vol. 3, has now become stabilized. The subjects covered include the physics and chemistry of fibrous materials ; fibre production ; conversion of fibres into finished yarns; fabric production; colouring matters; colouring of textiles; finishing of textile fabrics; analysis, testing, grading and defects ; laundering and dry cleaning; building and engineering; and industrial applications of textiles.

Some thirty authors contribute the twenty-six subsections and, resulting from the policy of the joint committee, the authorship has changed considerably so that in Vol. 5 only seven of the sub-sections have the same authors as in Vol. 3 and only three authors of Vol. 1 remain as contributors to Vol. 5. However, the high standard set by Vol. I has been maintained.
In Vol. 4 the physics and physical testing of fibrous materials was brought under one authorship to avoid overlapping, and in Vol. 5 physical testing has been transferred to its rightful place under the general heading of analysis, testing, grading and defects. Unfortunately, some unnecessary repetition has occurred ; for example, references $24,25,44,45,48$ in the section on physical testing duplicate references $72,73,77,76,90$ in the section on physics.

In the period under review there has been a rapid expansion in the production of synthetic fibres, and it is not surprising to find a large number of papers concerned with the difficult problem of their dyeing and with applications in which their characteristic properties can be used with advantage. It should be noted that many of the so-called new fibres being produced are basic types with new trade names. Numerous patents covering fibre-forming polymers have been filed, but fibres from them will not be produced commercially unless they have really outstanding properties. The natural fibres have not been neglected. Thus, the cotton fibre has received much attention, and the resulting modifications such as cyano-ethylated cotton, together with the growth of resin treatment and embossed finishes, promise to open up new applications. Many theoretical papers with a direct bearing on the spinning and preparation processes have appeared and will influence the design of machines to give improved quality and higher productivity per operator. The dyeing of fibres appears to be passing through a period of consolidation of the new ideas published during the past five years. In printing, interesting papers on engraving have overshadowed those on mechanical invention.

There are some three thousand references in each volume to scientific and technical publications and to British and American patents; but this does not mean that the "Reviews" are simply catalogues. The accounts are essentially readable, so that one can start anywhere and become so engrossed that the end of a section is reached all too soon. Extensive author and subject indexes enable the reader to find something he has read about and may wish to read again; they also help when using the "Reviews" as source books of information. All who have taken part in producing these volumes are to be congratulated.

\section{THE STORY OF THE VITAMINS}

\section{Vitamins in Theory and Practice}

By Dr. Leslie J. Harris. Fourth edition. Pp. xxii + 366. (Cambridge: At the University Press, 1955.) 35s. net.

A FTER three editions of this book between 1935 $A$ and 1938, we have had to wait seventeen years for the fourth edition. It can be said at once that Dr. L. J. Harris has again produced by far the most readable, indeed fascinating, account of the vitamins which has yet appeared.

In simple language and in the clearest style, Dr. Harris tella the story of how the existence of the vitamins was discovered and how each was recognized and defined. The story is enthralling; so often one has read the same facts and been left quite unmoved by a cold recitation of dates and data-perhaps because wo are too much concerned about the very latest developments and forget how exciting the earlier story is. Especially we overlook the brilliant work of some of the earlier investigators and how much we can still learn from their approach and 